Supplementary Information for:

\title{
Improved Mobility of Magnetite Nanoparticles at High Salinity with Polymers
}

\section{and Surfactants}

\author{
Anthony A. Kmetz ${ }^{1 \dagger}$, Matthew D. Becker ${ }^{1 \ddagger}$, Bonnie A. Lyon ${ }^{1}$, Edward Foster ${ }^{2}$, Zheng Xue ${ }^{2}$, Keith P. \\ Johnston $^{2}$, Linda M. Abriola ${ }^{1}$, Kurt D. Pennell ${ }^{1^{*}}$ \\ ${ }^{1}$ Department of Civil and Environmental Engineering, Tufts University, Medford, Massachusetts 02155, \\ United States \\ ${ }^{2}$ McKetta Department of Chemical Engineering, The University of Texas at Austin, Austin, Texas 78712, \\ United States
}

*Corresponding Author: kurt.pennell@tufts.edu (K.D.P.)

Current affiliations:

${ }^{\dagger}$ Aramco Research Center - Boston, 400 Technology Square, Cambridge, Massachusetts 02139, United States

${ }^{\ddagger} J$ ohn and Willie Leone Family Department of Energy and Mineral Engineering and EMS Energy Institute, The Pennsylvania State University, University Park, Pennsylvania 16802, United States 


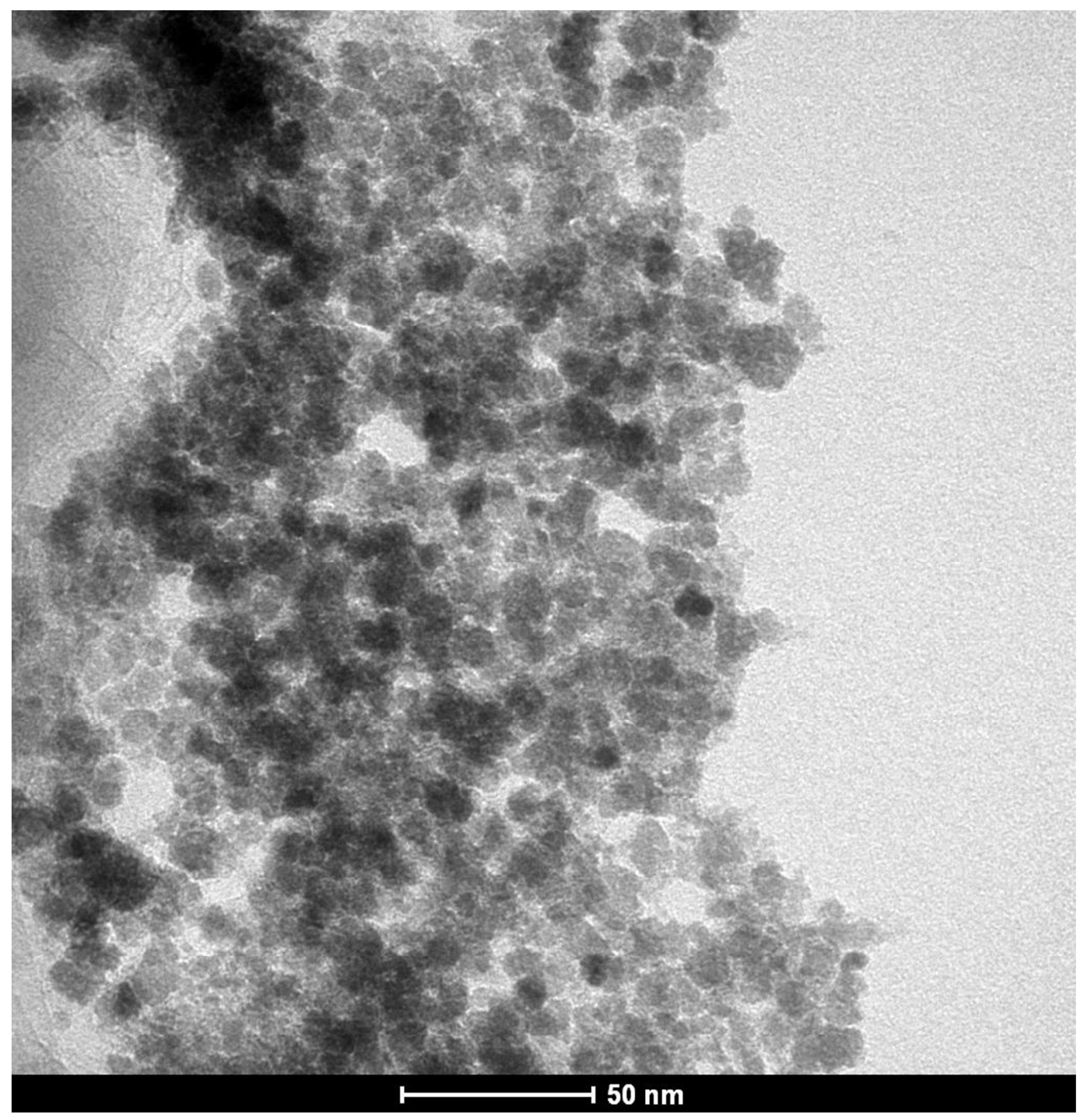

Figure S1. Transmission electron microscopy (TEM) image of a TEOS AMPs-co-AA coated iron oxide nanoparticle cluster. 
(a)

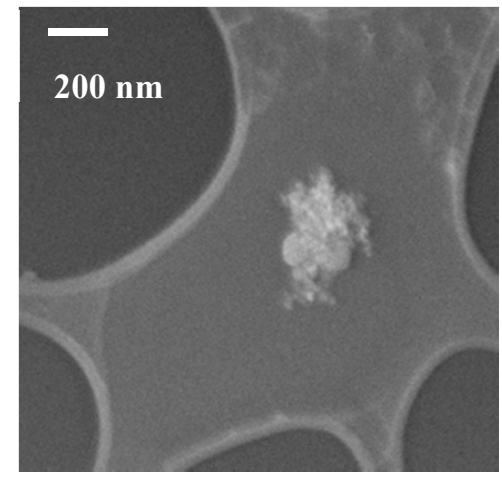

(b)

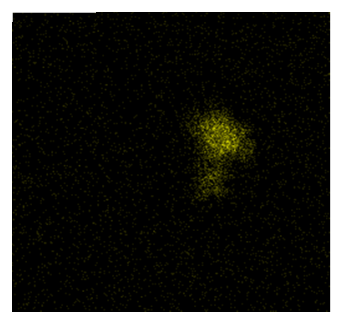

Iron

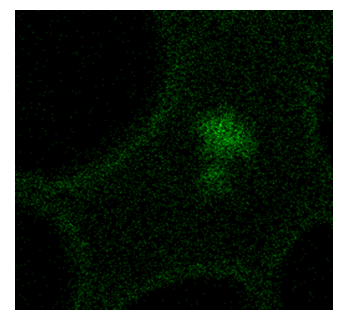

Oxygen

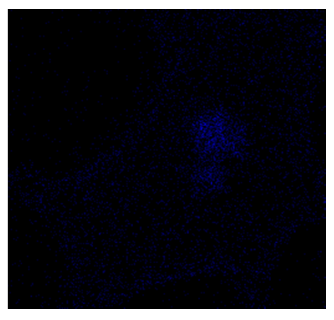

Silica

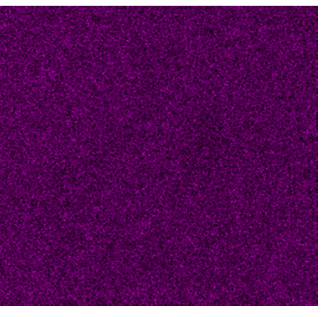

Copper

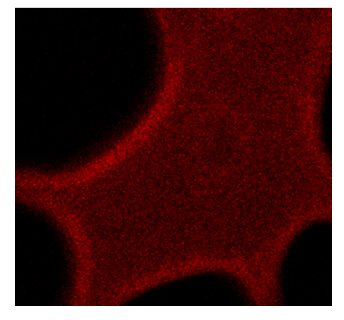

Carbon

Figure S2. (a) Transmission electron microscopy (TEM) image with (b) energy dispersive X-ray spectroscopy (EDS) mapping of nMag aggregate. The sample was prepared by drop-casting $5 \mu \mathrm{L}$ of an nMag suspension $(2,500 \mathrm{mg} / \mathrm{L}$ in deionized water) onto a lacey carbon on 300 mesh copper TEM grid. EDS mapping was performed on a JEOL 2010 TEM in annular dark field scanning TEM (STEM) mode, operated at $200 \mathrm{kV}$. 


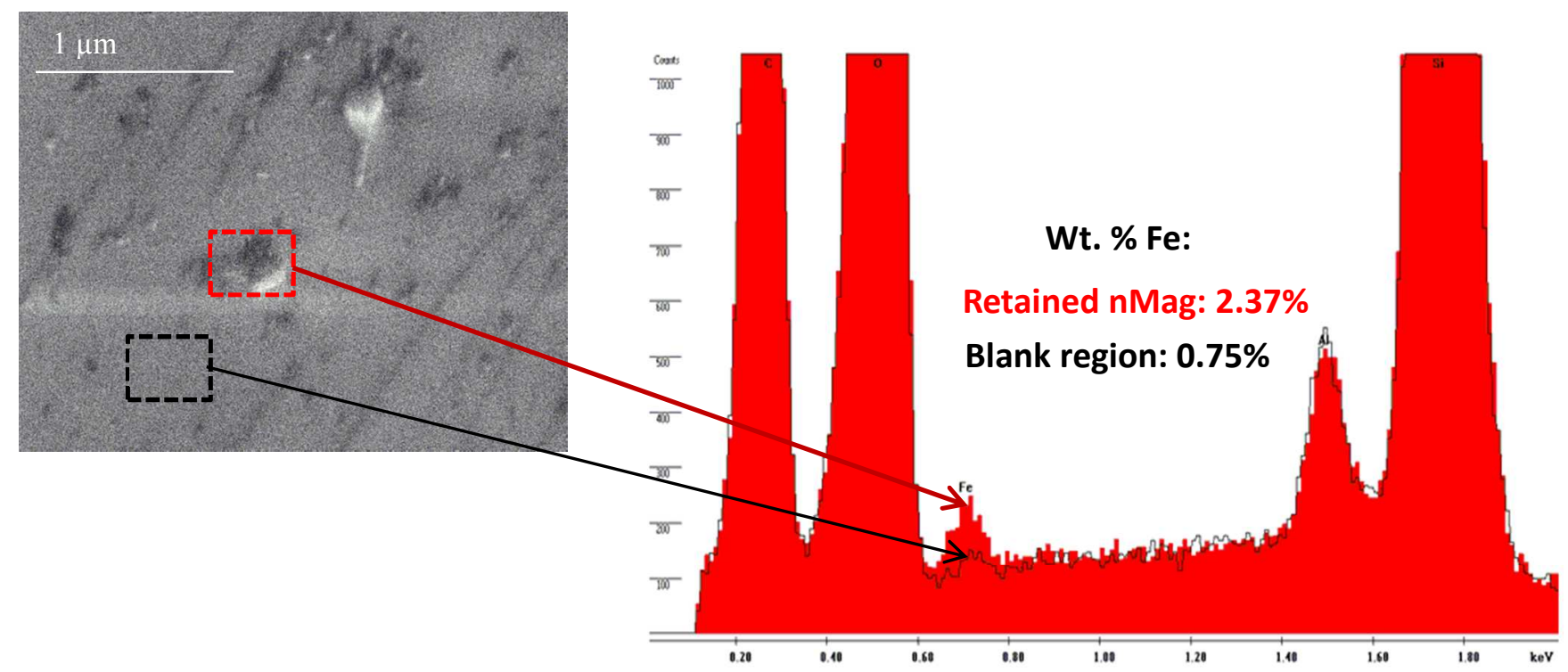

Figure S3. Energy dispersive x-ray spectroscopy (EDS) spectrum of nMag attached to Ottawa Sand (red) overlain with blank Ottawa sand spectrum (black line) obtained using a Supra55VP field emission scanning electron microscope $(\mathrm{SEM})$ in variable pressure mode, EHT voltage $=10 \mathrm{kV}$. 

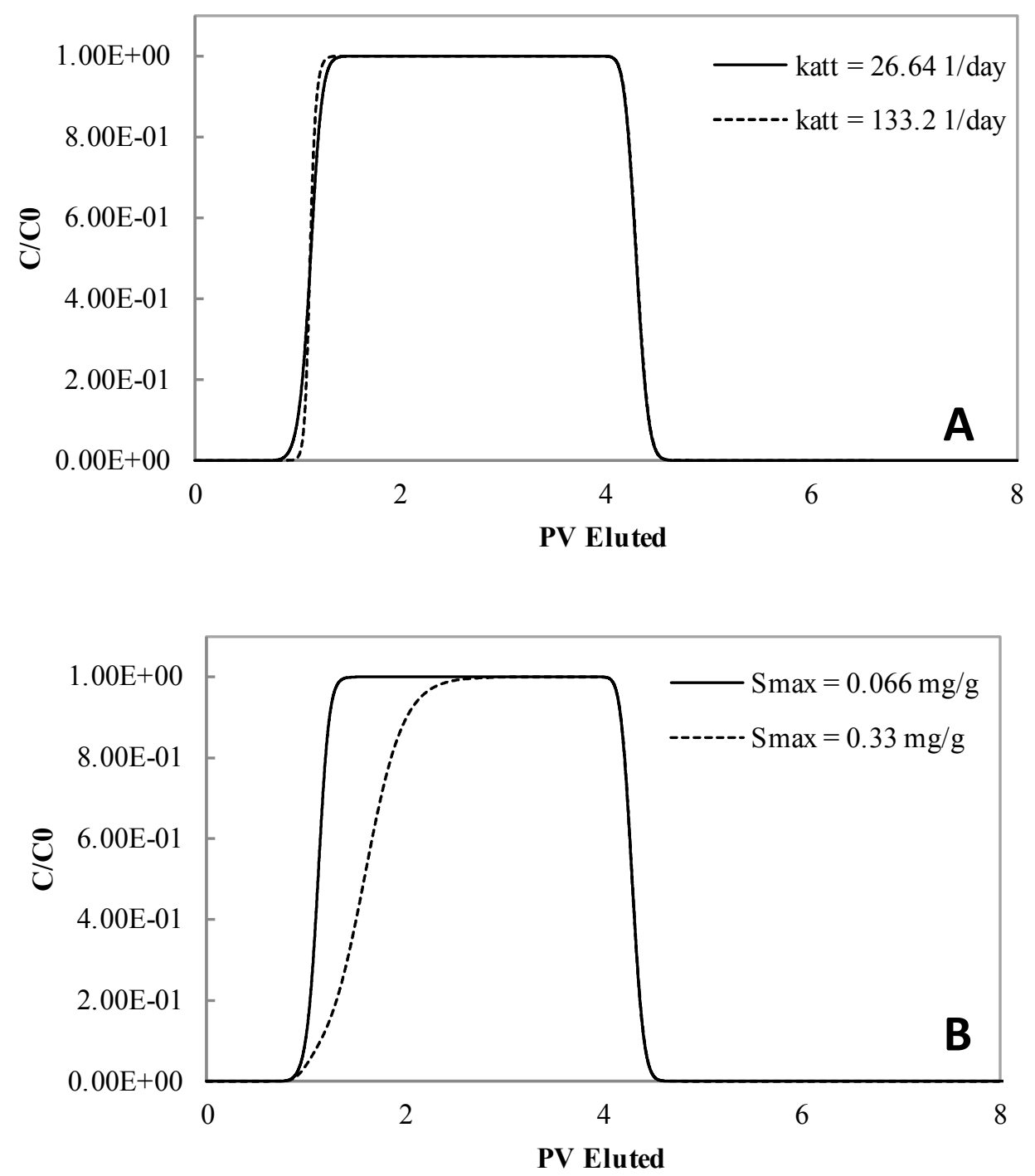

Figure S4. Model sensitivity to $\mathrm{k}_{\mathrm{att}}(\mathrm{A})$ and $\mathrm{S}_{\max }(\mathrm{B})$ for the $2,500 \mathrm{mg} / \mathrm{L} \mathrm{nMag}$ injection experiment in 4050 mesh Ottawa Sand. Here, $k_{\text {att }}(A)$ and $S_{\max }(B)$ were increased five fold to visualize the influence of each parameter on breakthrough curve shape. This result demonstrates the limited sensitivity of breakthrough curve shape to $k_{\text {att }}$ and the significant sensitivity of breakthrough curve shape to $S_{\max }$. 